Journal of

Cancer Research and Therapeutic Oncology

\title{
Vascular Retroperitoneal and Pelvic Leiomyosarcoma a Rare Disease Requiring Complex Surgery
}

Sacoto Urgilez $\mathrm{D}^{1, *}$, Rodriguez $\mathrm{M}^{1}$, Romero $\mathrm{JM}^{2}$, Cerdan $\mathrm{G}^{1}$, Martin $\mathrm{B}^{1}$, Artigas $\mathrm{V}^{1}$

${ }^{1}$ Department of General and Digestive Surgery, Hospital de la Santa Creu i Sant Pau. Sant Pau Biomedical Research Institute, IIB-Sant Pau. Autonomous University of Barcelona. Spain

${ }^{2}$ Departament of Angiology and Vascular Surgery, Hospital de la Santa Creu i Sant Pau. Sant Pau Biomedical Research Institute, IIB-Sant Pau. Autonomous University of Barcelona. Spain

${ }^{*}$ Corresponding author: David Sacoto Urgilez, Department of General and Digestive Surgery, Hospital de la Santa CreuiSant Pau, Carrer de SantQuintí, 89, 08041 Barcelona, Spain. E-mail: dsacoto@santpau.cat

Received Date: January 09, 2019 Accepted Date: January 18, 2020 Published Date: January 21, 2020

Citation: Sacoto Urgilez D (2020) Vascular Retroperitoneal and Pelvic Leiomyosarcoma a Rare Disease Requiring Complex Surgery. J Cancer Res Therap Oncol 8: 1-5.

\section{Article Highlights}

Type of Research: Single-center retrospective analysis

Key Findings: Retroperitoneal and pelvic LMS tumors are rare and aggressive, 27\% of patients experienced local recurrence, $75 \%$ in the form of pulmonary metastases. Currently, $27 \%$ of patients are in complete remission after a minimum follow-up of 12 months. DFS was 13.3 months, the OS mean (SD) was 43.3 (37.6) months and the OS rate was $56 \%$.

Take-home Message: The treatment that currently yields the best results of Retroperitoneal and pelvic LMS tumors is local control based on radical surgery (R0 resection)

Table of Contents Summary: This retrospective single-center study analyzed presentation, management and outcome of 11 patients with retroperitoneal and pelvic leiomyosarcomas. These types of tumors are rare and usually aggressive. The best treatment is local control based on radical surgery (R0 resection) and chemotherapy and/or radiotherapy.

(C)2020 The Authors. Published by the JScholar under the terms of the Creative Commons Attribution License http://creativecommons.org/licenses/ by/3.0/, which permits unrestricted use, provided the original author and source are credited. 


\section{Introduction}

Retroperitoneal and pelvic leiomyosarcomas (LMS) of vascular origin represent $0.5 \%$ of all sarcomas, with only around 300 cases described in the literature to date. Since clinical presentation is typically nonspecific, LMS diagnosis is often delayed. Women are twice as likely to develop the disease, which typically appears in the fifth or sixth decade of life [1]. The most frequent LMS site is the inferior vena cava (VC). Management of these patients needs to be multidisciplinary. Radical surgery is the treatment of choice, as it is the best means of locally controlling the disease. Recurrences are common, however, and signal a poor prognosis [2].

\section{Methods}

For our retrospective analysis of follow-up for a cohort of patients who had undergone LMS surgery in our hospital between 2008 and 2018, we collected data on demographics, intervention type, complications, recurrence rate, reoperation rate, disease-free survival (DFS) and overall survival (OS). Procedures were in accordance with the Helsinki Declaration of 1975, as revised in 1983. Informed consent was obtained from each patient. Extracted data were input to a database built with Microsoft Excel (Microsoft Corporation), and statistical analyses were performed with SPSS version 18 (PASW Statistics for Windows).

\section{Results}

The sample included 11 patients diagnosed with leiomyosarcoma with the previous biopsy, all patients underwent surgery, mean (SD) age 52 (10.6) years (range, 33-74 years), 91\% of whom were women, and $73 \%$ of whom had comorbidities (Table 1).

\begin{tabular}{|l|l|}
\hline Comorbidities & $\%$ \\
\hline Hypertension & $54.55 \%$ \\
\hline Diabetes mellitus type 2 & $18.18 \%$ \\
\hline High cholesterol & $9.09 \%$ \\
\hline Chronic obstructive pulmonary disease & $9.09 \%$ \\
\hline Pulmonary embolism & $9.09 \%$ \\
\hline Cerebrovascular accident & $9.09 \%$ \\
\hline Ischemic cardiomyopathy & $9.09 \%$ \\
\hline
\end{tabular}

Table $\mathrm{N}^{\circ} 1$ : Comorbidities
The mean (SD) American Society of Anesthesiologists (ASA) surgical risk score was ASA 2 (ASA 1). The median time from the appearance of symptoms to diagnosis was 8 months (range, 6-24 months). Three patients had pulmonary metastases at diagnosis. Just over a third of patients (36\%) underwent neoadjuvant chemotherapy aimed at reducing tumor size and enhancing resectability, and the remaining patients (64\%) directly underwent surgery (Table 2).

\begin{tabular}{|l|l|l|}
\hline Location & N & $\begin{array}{l}\text { Surgical } \\
\text { approach }\end{array}$ \\
\hline Vena cava & 7 & Open \\
\hline Left iliac vein & 1 & Open \\
\hline Left renal vein & 1 & Open \\
\hline Right gonadal vein & 1 & Laparoscopy \\
\hline Right iliac vein & 1 & Open \\
\hline
\end{tabular}

Table 2. LMS site and surgical approach.

The interventions were performed by a team of oncologist surgeons and a vascular surgeon. Mean (SD) operating time was 268 (69) minutes. R0 (negative margin), R1 (microscopic positive margin), R2 (macroscopic positive margin) resections were performed in $45.5 \%, 45.5 \%$ and $9 \%$ of patients, respectively.

In $73 \%$ of patients, resection was en bloc, i.e., (Figure 1) it included adjacent organs such as a kidney, the spleen or the colon; in the remaining 27\% (Figure2), only the tumor was resected (Table 3). Mean (SD) blood loss during surgery was 500 (580) cc and $36 \%$ of patients required blood transfusion during surgery (mean $900 \mathrm{cc}$ ). No patient required reoperation. Postoperative complications according to the Clavien-Dindo classification occurred in $63 \%$ of patients ( $36 \%$ grade I and $27 \%$ grade II).

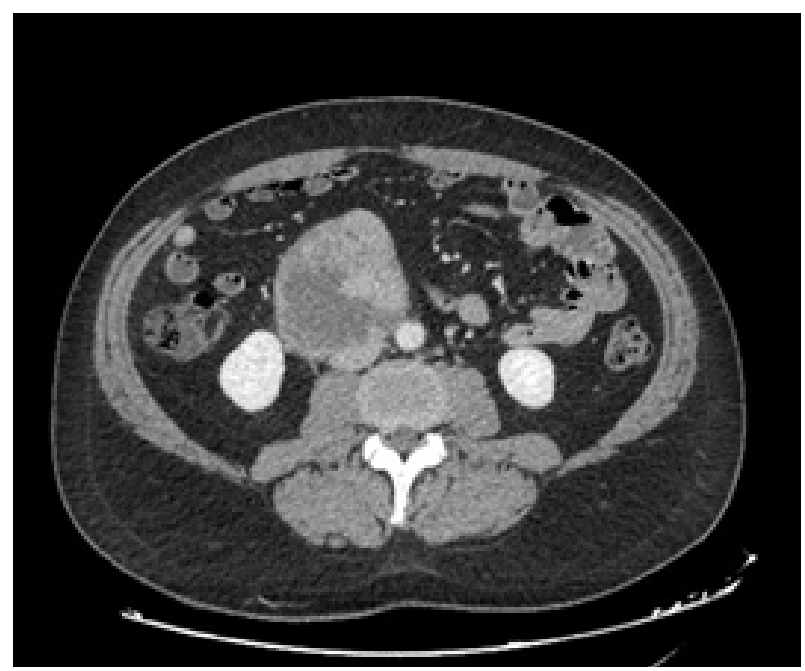

Figure 1: Leiomyosarcoma of vena cava 


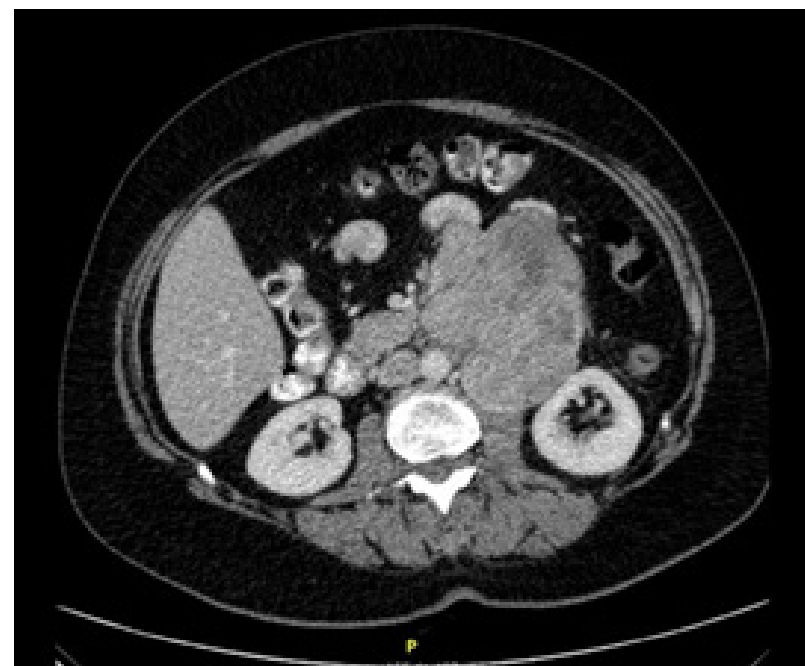

The median hospital stay was 28 days (range, 7-69 days). No patient died during surgery and all were discharged. During follow-up, $27 \%$ of patients are in complete remission after a minimum follow-up of 12 months. $27 \%$ of patients experienced local recurrence.74.1\% had disease relapse in the form of pulmonary metastases and a single patient relapsed with breast and liver metastases. All patients received adjuvant chemotherapy and radiotherapy. Mortality during follow-up was 45\% (5 patients); one patient died a year after surgery because of a primary brain tumour, but had no LMS recurrence during followup.

Figure 2: Leiomyosarcoma of left renal vein

\begin{tabular}{|c|c|c|c|c|c|c|}
\hline Patient & $\begin{array}{l}\text { Tumour } \\
\text { size } \mathrm{cm})\end{array}$ & Surgery & Reconstruction & $\begin{array}{l}\text { Resection } \\
\text { type }\end{array}$ & $\begin{array}{l}\text { FNLCLCC } \\
\text { grade }\end{array}$ & $\begin{array}{l}\text { AJCC } \\
\text { stage }\end{array}$ \\
\hline 1 & 7.8 & $\begin{array}{l}\text { Anterior vena cava wall tumour } \\
\text { resection }\end{array}$ & $\begin{array}{l}\text { Partial resection of the } \\
\text { vein and suture }\end{array}$ & R0 & 3 & T2N0M0 \\
\hline 2 & 12 & $\begin{array}{l}\text { Anterior vena cava wall tumour } \\
\text { resection + left nephrectomy for } \\
\text { renal involvement }\end{array}$ & $\begin{array}{l}\text { Partial resection of the } \\
\text { vein and suture }\end{array}$ & $\mathrm{R} 1$ & 3 & T3N0M0 \\
\hline 3 & 9 & $\begin{array}{l}\text { Vena cava tumour resection }+ \\
\text { nephrectomy }+ \text { aorta wall }\end{array}$ & $\begin{array}{l}\text { Vena cava ligature }+ \\
\text { aorta prosthesis }\end{array}$ & $\mathrm{R} 1$ & 3 & T3N0M0 \\
\hline 4 & 13 & $\begin{array}{l}\text { Vena cava tumour resection }+ \\
\text { nephrectomy }+ \text { gallbladder }+ \\
\text { suprarenalectomy }\end{array}$ & Vena cava ligature & $\mathrm{R} 1$ & 2 & T2N0M0 \\
\hline 5 & 10 & $\begin{array}{l}\text { Renal vein tumour resection }+ \\
\text { nephrectomy }\end{array}$ & Vein ligation & $\mathrm{R} 1$ & 2 & T2N0M0 \\
\hline 6 & 11 & Gonadal vein tumour resection & Ligature & R0 & 2 & T2N0M0 \\
\hline 7 & 5 & $\begin{array}{l}\text { Lateral vena cava wall tumour } \\
\text { resection }\end{array}$ & $\begin{array}{l}\text { Partial resection of the } \\
\text { vein and suture }\end{array}$ & $\mathrm{R} 1$ & 3 & T2N0M0 \\
\hline 8 & 7 & $\begin{array}{l}\text { Right external iliac vein tumour } \\
+ \text { femoral nerve resection }\end{array}$ & $\begin{array}{l}\text { Synthetic femoral ar- } \\
\text { tery bypass prosthesis }\end{array}$ & R0 & 3 & T3N0M1 \\
\hline 9 & 5 & $\begin{array}{l}\text { Left renal vein tumour + pan- } \\
\text { creatic tail + left colon + kidney } \\
+ \text { psoas muscle resection }\end{array}$ & Vein ligation & R0 & 3 & T3N1M1 \\
\hline 10 & 5.5 & Left iliac vein tumour & Ligature & $\mathrm{R} 2$ & 3 & T3N0M0 \\
\hline 11 & 12 & $\begin{array}{l}\text { Gonadal vessel anterior wall } \\
\text { tumour + vena cava resection }\end{array}$ & $\begin{array}{l}\text { Anterior vena cava } \\
\text { wall suture }\end{array}$ & R0 & 3 & T3N0M1 \\
\hline
\end{tabular}

Table 3: Retroperitoneal and pelvic characteristics 
Disease-free survival was 13.3 months. The Overall survival rate was $56 \%$, for a mean (SD) of 43.3 (37.6) months. There were no statistically significant differences when comparing resection type ( $R 0, R 1$ or $R 2$ ) with survival ( $p>0.05$ ), a result that is, however, probably due to the small size of our sample.

\section{Discussion}

Because retroperitoneal and pelvic LMS are usually detected when already at an advanced stage, the prognosis is generally poor [3]. Symptoms include abdominal or back pain (70\%), oedema of the lower legs (15\%), abdominal distension (9\%), weight loss (11\%) and, more infrequently, VC thrombosis or inferior pulmonary embolism [4]. Growth patterns in relation to the affected venous vessel may be endoluminal (most frequently), extraluminal or mixed [5]. Distant metastasis occurs via the lymphatic route to regional lymph nodes, and via the haematologic route to the lungs, liver, and bones.

LMS in the inferior VC are classified by level according to the relationship with neighboring structures: (a) level 1 corresponds to tumours in the infrarenal inferior VC (38\% of cases); (b) level 2 corresponds to tumours located between the suprahepatic veins and the entrance to the renal veins (46\% of cases), and (c) level 3 corresponds to tumours located between the right atrium and the entrance to the suprahepatic veins $(16 \%$ of cases) [5]. In our case, 6 patients had tumors whose origin was vena cava. Four (36.4\%) correspond to level I and two (18.2\%) cases to level one. The rest were located in the renal vein, gonadal and iliac vein

The mainstay of treatment is surgery involving tumour resection with negative margins (R0). While resection of level 1 tumours is a relatively simple procedure inexperienced hands, resection of level 2 and 3 tumours may require complex procedures. The type of procedure is determined by the level of involvement of adjacent structures, by tumour size and by the presence or absence of collateral circulation compensating for possible occlusion of the affected venous vessels [6]. The surgical options include partial resection of the vein and bovine pericardium patch angioplasty when tumoral involvement is less than $75 \%$ of the circumference, or complete resection with venous or prosthetic graft when involvement is greater than 75\% [7]. When the tumor totally occludes the venous vessels, resulting in important collateral circulation, the inferior VC or iliac can be ligated until venous drainage of the extremities by the collateral pathway. However many of the collaterals are resected during tumor removal and that vena cava ligation in those instances is associated with over $50 \%$ significant lower extremity edema [6].
In our case, the reconstruction options planned were: suture of the anterior or lateral vein, replacement with PTFE or Dacron prostheses or simply tumor resection and vein ligation. In four cases we performed suture of the affected wall of the vena cava since the tumor involvement of the vein circumference was limited without significantly compromising its diameter. In 6 cases ligation of the affected vein was performed, 3 of which were vena cava. Two patients had significant edema in the lower extremities that improved with the use of compression stockings. Case No. 3 required prosthetic replacement of a segment of the aorta due to tumor involvement. Case No. 7, a prosthetic iliac femoral bypass was used. In case No. 10, reconstruction of the iliac vessels was planned with a prosthesis but it was not carried out because the surgery was complicated by significant bleeding and bone involvement of the tumor, so the vessels were ligated.

The use of postoperative anticoagulant or antiaggregant treatment will depend on the type of repair performed. When a prosthesis is used, some authors recommend anticoagulation treatment for 6 months followed by prophylactic antiaggregant treatment [6-7], while others report good results without anticoagulation treatment [8]. In our case, we used the former regimen when a prosthesis was used, and anticoagulation treatment for 6 months in cases of a simple repair of a large vessel (iliac or femoral).

Neo-adjuvant chemotherapy is an alternative for unresectable tumours, with subsequent surgical removal recommended if the tumour recurs after chemotherapy. According to the European Society of Medical Oncology (ESMO) guidelines, radiotherapy is indicated in selected cases with superficial low/ high-grade tumours measuring $>5 \mathrm{~cm}$ and deep low-grade tumours measuring $<5 \mathrm{~cm}$. As for deep low-grade tumours measuring $>5 \mathrm{~cm}$, these should be discussed individually with a multidisciplinary team, bearing in mind the anatomical site and looking for a trade-off between expected risks and benefits (level of evidence 2C) (9). All of our patients were treated with both adjuvant chemotherapy and radiotherapy.

Vascular LMS recur frequently and require multiple reoperations. As predictors of poorer overall survival, Alkhalili and colleagues [1] identified advanced age, larger tumours, enbloc resections, adjuvant chemotherapy, and incomplete resection. The fact that histological grade was not a significant predictive factor was interpreted as being due to the aggressiveness of the sarcoma and, in some of the included series, possibly due to incomplete pathological reports [1]. 
Wachtel and colleagues [10] reported mean DFS and OS of 12 and 23 months, respectively, DFS rates at 1 and 5 years of $57 \%$ and $6 \%$, respectively, and OS rates at 1 and 5 years of $92 \%$ and $55 \%$, respectively. In our case, DFS was 13.3 months, the OS mean (SD) was 43.3 (37.6) months and the OS rate was $56 \%$.

\section{Conclusion}

Retroperitoneal and pelvic LMS tumours are rare and usually aggressive. The option that currently yields the best results is local control based on radical surgery ( $\mathrm{R} 0$ resection) and chemotherapy and/or radiotherapy. We found no significant differences in survival compared to the type of resection.

\section{References}

1. Alkhalili E, Greenbaum A, Langsfeld M, Marek J, Rana MA, Glew R, et al. (2016) of the Inferior Vena Cava: A Case Series and Review of the Literature. Ann Vasc Surg 33: 245-251.

2. Murguía-Pérez M, López-Zúniga D, Cruz-Gordillo AG, León-MartínezG, Navarro Córdoba FJ, et al. (2011) Leiomiosarcoma de la vena cava inferior. Presentación de un caso y revisión del cuadro clinicopatológico. Rev Esp Patol 44: 132- 135.

3. Centeno-Flores M, Zaldívar-Reyna O, Abohar Z, Medina-Ramírez CG, Padrón-Rivera LH. et al. (2011) Leiomiosarcoma retroperitoneo primario de vena cava. Reporte de un caso y revisión de la literatura. RevHospJuaMex 78: 46-49.

4. Ceyhan M, Danaci M, Elmali M, Ozmen Z, et al. (2007) Leiomyosarcoma of the inferior vena cava. DiagnInterv Radiol 13:140-143.

5. Hartman DS, Hayes WS, Choyke PL, Tibbetts GP, et al. (1992) From the archives of the AFIP. Leiomyosarcoma of the retroperitoneum and inferior vena cava: radiologic-pathologic correlation. Radiographics. 12: 1203-1220.

6. Spinelli A, Schumacher G, Benckert C, Sauer IM, Schmeding M, Glanemann M, et al. (2008) Surgical treatment of a leiomyosarcoma of the inferior vena cava involving the hepatic and renal veins confluences: Technical aspects EJSO 34: 831-835.

7. Kieffer E, Alaoui M, Piette JC, Cacoub P, Chiche L (2006) Leiomyosarcoma of the inferior vena cava: Experience in 22 cases Ann Surg 244: 289-295.
8. López-Ruiz JA, Tallón-Aguilar L, Marenco-de la Cuadra B, López-Pérez J, Oliva-Mompeán, F., \& Padillo-Ruiz J (2017) Leiomyosarcoma of the inferior vena cava. Case report and literature review. Cirugía y Cirujanos (English Edition) 85: 361-365.

9. (2018) The ESMO/European Sarcoma Network Working Group. Soft tissue and visceral sarcomas: ESMO-EURACAN Clinical Practice Guidelines for diagnosis, treatment, and followup. Ann Oncol 29 : iv51-iv67.

10. Wachtel H, Gupta M, Bartlett EK, Jackson BM, Kelz RR, Karakousis GC, et. al. (2015) Outcomes after resection of leiomyosarcomas of the inferior vena cava: A pooled data analysis of 377 cases. Surgical Oncology 24: 21-27.

Submit your manuscript to a JScholar journal and benefit from:

q Convenient online submission

ฯ Rigorous peer review

- Immediate publication on acceptance

q Open access: articles freely available online

q High visibility within the field

I Better discount for your subsequent articles

Submit your manuscript at http://www.jscholaronline.org/submit-manuscript.php 